\title{
Ein schöner Beruf ... Ethik des Bestattungsberaters
}

Während meiner Zeit als Kantonsarzt in einer Abteilung, die unter anderem für die Überprüfung der Bestattungsinstitute zuständig war, konnten wir bei einigen der Unternehmer zuweilen fragwürdige, sehr profitorientierte Praktiken beobachten. In einem kürzlich erschienenen Buch [1] beschreibt ein Bestattungsunternehmer seine Tätigkeit hingegen als einen schönen Beruf ... Muss das überraschen? Der Alltag eines Bestattungsberaters - so die vom Autor bevorzugte Bezeichnung - besteht in der Betreuung jener, die gerade einen nahestehenden Menschen verloren haben. An sich kein attraktives Berufsbild, aber das Buch «La mort humanisée» zeigt auf, dass man das «Bündnis» mit dem Tod auch als schöne Aufgabe betrachten kann.

Der Autor versichert, «der Bestattungsberater versuche stets, jedwede Machtausübung über die Trauernden zu vermeiden», und führt dabei an mehreren Stellen Möglichkeiten des Machtmissbrauchs an. Dies kommt der ärztlichen Ethik sehr nahe. "Anliegen der Ethik ist die Förderung der Selbstbestimmung des anderen», sagt der Medizinethiker Jean-François Malherbe. Das gilt für die Gesundheitsberufe, die Sozialarbeit, die Arbeit im Erziehungs- und Bildungswesen und auch für den Bestattungsberater.

Berauscht von den Fortschritten der Medizintechnik, wollte das Ende des 20. Jahrhunderts den Tod nicht mehr als Teil des Lebens sehen und ihn hinter einem Vorhang verstecken. «Die Verstorbenen störten, und die Bestattung musste so diskret wie möglich ablaufen.» Eine Zeit, in der es in den Spitälern hiess: «Hier wird man geheilt, hier stirbt man nicht.» Flucht und Blindheit vor der nahezu alltäglichen Realität ... Heute weiss man wieder, dass Leben und Tod untrennbar zusammengehören, sich nicht absolut feindlich gegenüberstehen*

Wichtig ist, sich der Bedeutung des gesprochenen Wortes bewusst zu sein - wobei dies selbstverständlich für alle Lebenssituationen gilt. Ein offenes Ohr, Fingerspitzengefühl und hohe Bereitschaft sind gefordert. Und grosse Bescheidenheit, denn die Beteiligten, selbst wenn es sich um professionelle Betreuende handelt, können nicht immer erahnen, was in einem Trauernden vorgeht. Besonders sensibel zu behandeln ist auch die Frage, wieviel Kontakt (gegebenenfalls auch körperliche Nähe) die Angehörigen noch, allein oder mit Begleitung, mit der verstorbenen Person wünschen, wann, wie lange und an welchem Ort der Verstorbene noch einige Stunden/Tage verbringt und welche Umgebung geeignet ist.

Ein grosser Teil des Buches besteht aus eindringlichen Geschichten aus der Erfahrung des Autors. Die Beispiele zeigen den richtigen (und zuweilen auch falschen) Umgang mit diesen Situationen. Es sind beeindruckende Zeugnisse von Todesfällen, die nie verkraftet, Knoten, die über 25 oder 30 Jahre nicht gelöst wurden und in deren Kern Ungesagtes oder Lügen um den Tod eines Angehörigen stecken ... Man kennt die alles vergiftende Wirkung von Familiengeheimnissen. Auch der Tod von Babys vor oder kurz nach der Geburt wird erwähnt. Ihm widmen Ärzte und Hebammen heute grössere Aufmerksamkeit, so dass Raum geschaffen wird für geeignete Rituale und Zeremonien.

Ich respektiere vollkommen, wenn sich jemand entscheidet, still und leise, ohne Zeremonie von uns zu gehen. Dennoch bin ich überzeugt, dass es wichtig ist, sich für den Tod Zeit zu nehmen, ihm die richtige Würdigung zu erweisen und die entsprechenden Formen zu wählen. Dem Nahestehenden «hilft die Überzeugung, alles erfüllt zu haben, was in seiner Macht stand, bei der Überwindung der Trauer». Auch wenn es dazu notwendig ist, neue Riten zu erfinden.

Denn Pittet zufolge wissen die Familien, was sie brauchen. Aufgabe des Bestattungsberaters sei es, sie über ihre Rechte in Kenntnis zu setzen und ihnen die für sie richtige Betreuung zukommen zu lassen. Die Bestattungsberater haben ihre $\mathrm{Zu}$ ständigkeiten, deshalb wendet man sich an sie. Ihre Aufgabe ist es aber auch, gemeinsam mit den Betroffenen den Weg abzustecken, wie sie am besten mit dem Tod umgehen können. Im Sinne einer Botschaft, die für alle Lebenssituationen gilt: Das Wichtigste ist, das Selbstvertrauen der Menschen zu stärken, nicht es zu leugnen oder zu schwächen.

Dr. Jean Martin, ehemaliger Kantonsarzt, Mitglied der Nationalen Ethikkommission

1 Pittet E. La mort humanisée. Le Mont s/Lausanne: Editions Ouverture; im Druck. 